\title{
THE RISK FACTORS IN POSTMENOPAUSAL OSTEOPOROSIS
}

\author{
Nurettin Aka, M.D. / Emel Balkan, M.D. \\ E. Zeynep Tuzcular Vural, M.D. / Eșref Yazıcıoğlu, M.D.
}

\begin{abstract}
Clinic of Gynecology and Obstetrics, Mayclarpaşa Numune Teaching Hospital, istanbul, Turkey
\end{abstract}

\begin{abstract}
Objective: The cause of post-menopausal osteoporosis is estrogen deficiency. The source and quality of estrogen changes during the postmenopausal period. In this period the main estrogen in the circulation is estrone and is formed by the aromatization process of androgens peripherally. This process depends upon the body mass and age of the patients. Therefore the aim of this study was to determine the relationship between risk factors and reduction of bone density in Turkish postmenopausal women.
\end{abstract}

Methods and Results: A hundred postmenopausal women were evaluated; their average age was 50.44 and their body mass index (BMI) were calculated $\left(\mathrm{kg} / \mathrm{m}^{2}\right)$. Their age, the duration of menopause and the presence/absence of smoking were taken into consideration. Bone mineral density assessment was done with Lunar DPX. The data obtained was evaluated by multiple regression analysis and $x^{2}$ test.

Conclusion: We found that BMI varies directly and the duration of menopause indirectly with bone mineral density. The age of the patient on its own is barely related to bone mineral density whereas a history of smoking has no effect.

Key Words: BMI and osteoporosis, Risk factors, Postmenopausal osteoporosis

\section{INTRODUCTION}

Osteoporosis is one of the major problems arising from estrogen deficiency in the postmenopausal period. Osteoporosis defines the reduction in bone density. In general, there are many factors leading to osteoporosis but the main cause of postmenopausal osteoporosis is the deficiency of estrogen. As follicular activity diminishes, 17- $\beta$ estradiol, the basic estrogen in the circulation is replaced by estrone which is basically produced from androstenedione by the enzyme extraglandular aromatase. The activity of extraglandular aromatase depends on age and body weight and increases two fold in the perimenopausal period.

It is now well known that the change in the trabecular bone in postmenopausal women depends on estrogen deficiency. $75 \%$ or more of the reduction in bone density during the first 15 years after menopause is caused by the deficiency of estrogen rather than aging.

Free androgens are converted to free estrogens in the skin and adipose tissues. The placement of the adipose cells in the body does not affect their activity. Women with central obesity possess a greater amount of androgens. Daily conversion of androstenedione to testosterone is less than $1,5 \%$ in postmenopausal women, However, in obese women, this ratio and the level of sex steroids in the circulation is also affected by the sex hormone binding globulin (SHBG) 
Thirty percent $30 \%$ of the estrogens in the circulation are bound to albumin, $69 \%$ bound to SHBG and $1 \%$ are free. The level of SHBG in the circulation is indirectly correlated with the body weight and for this reason evident weight gain results in a decrease in the levels of SHBG, and an increase in the free sex steroid levels.

Estrogen deficiency also leads to a decrease in calcitonin levels secreted from the thyroid gland. Calcitonin reduces serum calcium levels by inhibiting the osteoclastic activity which in turn means that it acts reversely to PTH's resorptive effect. Estrogens consequently inhibit the effects of PGE2 and interleukine which increase bone resorbtion. Estrogens stimulate the local production of transforming growth Factor-B (TGF-B) and insulin like growth factor-1 (IGF-1) which in turn stimulate bone formation. A significant increase in urinary calcium is detected in women who do not take estrogen replacement therapy.

The aim of this study was to determine the relationship between risk factors (Table I) and reduction of bone density in Turkish postmenopausal women.

\section{MATERIALS AND METHODS}

A hundred patients presenting to the Haydarpaşa Numune State Hospital Department of Gynecology and Obstetrics Menopause Outpatient Clinic, between 1994-1996 were randomly selected.

Table I. The factors increasing the risk of postmenopausal osteoporosis

*high percentage of weight loss

*alcohol abuse

"high sodium intake

"smoking

*high catfein intake

" high protein intake

*high phosphate intake

"Caucasian or Asian ethnic origin

"presence of family history

"low caicium intake

*early menopause or oopherectomy

"sedantary life style

*nulliparity

"secondary losses.
We explored the relationship between age, duration of menopause, cigarette smoking and body mass index and the reduction of bone density. The data obtained was evaluated statistically by multiple regression analysis and the chi-square test.

Body-mass index (Quetelet Index) was measured by dividing the body weight to body surface (metric system).

Bone density was evaluated with Lunar DPX dualphoton absorptiometer using measurements of L2-L4 spine BMD (bone mineral density) and proximal femur BMD values.

Reference values for young adults and $Z$ scores were based on the evaluation of fracture risks. According to this:

* BMD values under $80 \%$ in young adults (defines the bone density loss as more than 20\%; $Z$ score less than 2 SD) indicate that the person is in the osteoporosis risk group. This group is called "group 1" in our study.

* Values under $70 \%$ in young adults (this defines bone density loss as more than 30\%; Z score less than $3 \mathrm{SD}$ ) indicate the absolute osteoporosis risk group. This group is called "group 2" in our study.

* Values under $60 \%$ for young adults (this defines bone density loss more than $40 \%$; Z score less than $4 \mathrm{SD}$ ) show that severe osteoporosis is present, and even minimal trauma may cause fracture. This group is called "group 3".

\section{RESULTS}

A total of 100 subjects were included in this study. The mean age, duration of menopause and BMI were 50.44 (range 29-67), 3.9 (range 118) and 26.47 (range 15-43), respectively. (Table II) None of the subjects had an illness which could result in a decrease in bone density.

Ninteen percent of the population were smokers and $81 \%$ non-smokers.

Osteodensitometric investigations showed that $45 \%$ of the selected patients had normal bone 
Table II. Age, duration of menopause and BMI of the sampled population

\begin{tabular}{|lccccc|}
\hline & MEAN & MIN & MAX & $\begin{array}{c}\text { STANDARD } \\
\text { ERROR }\end{array}$ & $\begin{array}{c}\text { STANDARD } \\
\text { DEVIATION }\end{array}$ \\
\hline AGE & 50.44 & 29 & 67 & 0.574 & 5.74 \\
$\begin{array}{l}\text { DURATION OF } \\
\text { MENOPAUSE }\end{array}$ & & & & & \\
(YEARS) & 3.9 & 1 & 18 & 0.375 & 3.75 \\
BMI & 26.47 & 15 & 43 & 0.46 & 4.60 \\
\hline
\end{tabular}

mineral density; $32 \%$ were in the risk group; $16 \%$ had osteoporosis and $7 \%$ had fracture risk with minimal trauma (Table III).

A borderline relationship was detected between bone mineral density and age by the one-way variance analysis (Table III).

A significant relationship was detected by oneway variance analysis between duration of menopause and bone density (Table III).

A significant relationship was detected by oneway variance analysis between $\mathrm{BMI}$ and bone density (Table III).

No relation was detected between cigarette smoking and bone mineral density $\left(x^{2}=1.333\right.$, $p=0.72$ )

\section{DISCUSSION}

Studies concerning risk factors in osteoporosis and its prevention carried out by Tuppurainen et al (1) for perimenopausal, and Biberoğlu et al (2) for postmenopausal women showed that fracture incidence increases with age, and that menopause affects the fracture formation risk more intensively than 5 years of chronological ageing. Kroger et al's (3) study on 1600 perimenopausal, Bauer (4) and McKnight et al's (5) studies concerning postmenopausal women revealed that reduction in bone mineral density is well correlated with the duration of menopause rather than with chronologic age, and that BMI shows positive correlation with bone mineral density. Kleerekoper (6), Johnell (7) and Suzuki et al (8) demonstrated that the menopausal period is a clear risk factor for osteoporosis. In their study in 1993, Nelson et al (9) reached the result that high $\mathrm{BMI}$ is not a preventive factor for osteoporosis. Dawson et al (10) stated in their study that high body weight is related to much more mineralized bone structure, but that this effect is only available when body weight reaches $110 \%$ of normal conditions; no concensus is present for the preventive effect of body weight; smoking increases the rate of bone loss and decreases bone mass.

However Kroger (3) and McKnight (5) showed in their study that smoking is not a risk factor for low bone mineral density; Bauer (7) defined in his study that smoking is an absolute risk factor causing bone density reduction.

In our study we found that bone density is negatively correlated with the duration of menopause but positively correlated with BMI $(p<0.05)$. Bone mineral density is well protected in women with a high weight-to-height ratio and $\mathrm{BMI}$ and the risk of postmenopausal osteoposis

Table III. Bone Mineral Density results of the sampled population, the relationship between bone mineral density and age, duration of menopause, and BM!

\begin{tabular}{|c|c|c|c|c|}
\hline $\begin{array}{l}\text { Bone Mineral } \\
\text { Density }\end{array}$ & $\begin{array}{l}\text { Percentage in the } \\
\text { Sampled Population }\end{array}$ & Mean Age* & $\begin{array}{l}\text { Mean Menopause * * } \\
\text { Time (year) }\end{array}$ & $\mathrm{BM} \mid * \cdots$ \\
\hline - Normal (no BMD loss) & $45 \%$ & 49.02 & 3 & 28 \\
\hline $\begin{array}{l}\text { - Risk Group } \\
\text { (BMO Loss more than 20\%) }\end{array}$ & $32 \%$ & 50.91 & 4 & 26 \\
\hline $\begin{array}{l}\text { - Osteoporosis Group } \\
\text { (BMD loss more than 30\%) }\end{array}$ & $16 \%$ & 52.75 & 6 & 23 \\
\hline $\begin{array}{l}\text { - Fracture risk with minimal trau } \\
\text { (BMD loss more than } 40 \% \text { ) }\end{array}$ & $7 \%$ & 52.14 & 7 & 21 \\
\hline \multicolumn{5}{|c|}{$* F$ value $=2.12 p=0.102 * F$ value $=4.2993 \quad p=0.0068 * F$ value $=3.433 \quad p=0.038$} \\
\hline
\end{tabular}


is lower than those with a low weight-to-height ratio and $\mathrm{BMI}$.

There is only a borderline relation between the patient's age and bone mineral density. The duration of the menopause ("the hypoestrogenic period") is more significant in reduction of bone mineral density than the age at which menopause begins.

We found no statistically significant relationship between smoking and osteoporosis ( $p>0.05$ ). There are many studies showing the relationship between cigarette consumption and osteoporosis with different results and our findings are generally not compatible with the current literature. We came to the conclusion that, because the ratio of cigarette consumption in Turkey in women over the age of 40 is low, this naturally affects statistical data. Different results may be available if larger cohort studies are carried out.

\section{REFERENCES}

1. Tuppurainen M, Honkanen R, Kroger H. Saarikoski S, Alhava E. Osteoporosis risk factors, gynaecological history and fractures in perimenopausal women - the results of the Kuopio Osteoporosis Risk Factor and Prevention Study. Maturitas 1993;17:89-100.

2. Biberoğlu KO, Yıldız A, Kandemir O. Bone mineral density in Turkish postmenopausal women. Int J Gynaecol Obstet 1993:41:153157.
3. Kroger $H$, Tuppurainen $M$, Honkanen $R$, Alhava E, Saarikoski S. Bone mineral density and risk factors for osteoporosis a population based study of 1600 perimenopausal women. Calcif Tissue Int 1994;55:1-7.

4. Bauer DC, Browner WS, Cauley JA, et al. Factors associated with appendicular bone mass in older women. The Study of Osteoporotic Fractures Research Group. Ann Intern Med 1993; I 18:657-665.

5. McKnight $A$, Steele $K$, Mills $K$, Gilchrist $C$, Taggart H. Bone mineral density in relation to medical and lifestyle risk factors for osteoporosis in premenopausal and postmenopausal women in general practice. Br J Gen Prac 1995:45:31 7-320.

6. Kleerekoper M, Nelson DA, Peterson EL, Wilson PS, Jacobsen G, Longco pe C. Body composition and gonadal steroids in older white and black women. J Clin Endocrinol Metab 1994;74:775-779.

7. Johnell O, Gullberg B, Kanis JA, et al. Risk factors for hip fracture in European women: the Medos study. Meditteranean Osteoporosis Study. I wbone Miner Res 1995;10:18021815.

8. Suzuki $N$, Yano T, Nakazawa $N$, Yoshikawa $H$, taketani $Y$. A possible rolc of estrone produced in adipose lissues in modulating postmenopausal bone density. Maturitas 1995:22:9- 12.

9. Nelson DA, Kleerekoper M, Peterson E, Parfitt AM. Skin color and body size as risk factors for osteoporosis. Osteoporos Int 1993;3:1823.

10. Dawson-Hughes B, Krall EA, Harris S. Risk factors for bone loss in healthy postmenopausal women. Osteoporos int 1993:3 Suppl 1: 27-31. 